\title{
Midwives' Knowledge of Non-Pneumatic Anti-Shock Garment and Associated Factors among Midwives Working in Public Hospitals of Jimma Zone, South- West Ethiopia.
}

Gemechu Sori Terefe ( $D$ 1gemechuter2014@gmail.com )

Jimma University

Gadisa Bedada Bekele

Jimma University

\section{Research}

Keywords: Knowledge, non-pneumatic anti shock garment, Midwives, postpartum haemorrhage

Posted Date: May 12th, 2020

DOI: https://doi.org/10.21203/rs.3.rs-27644/v1

License: (c) (i) This work is licensed under a Creative Commons Attribution 4.0 International License. Read Full License 


\section{Abstract}

Background: The non-pneumatic anti-shock garment is a unique, simple, life-saving first-aid device made of neoprene and velcro. Neoprene is a stretchy material, and Velcro is a "hook and loop" material that closes things tightly . I n 2017 e very day, approximately 810 women died from preventable causes related to pregnancy and childbirth . From this death about $94 \%$ of all maternal deaths occur in low and lower middleincome countries.

Objective: The objective of this study was designed to assess Midwives knowledge of non-pneumatic antishock garment and associated factors among Midwives.

Methods: Facility based a quantitative cross-sectional studies design method was employed among 150 Midwives. Data was collected by pretested semi-structured self-administered questionnaire. The collected data were checked, coded and entered into Epi-data version 3.1 by double data enter and exported to SPSS version 23 for analysis. Bivariable and multivariable logistic regression were done to identify factors associated with Midwives' Knowledge of non-pneumatic anti-shock garment.

Results: Eighty one (54\%) of Midwives have good knowledge of non-pneumatic anti-shock garment. Having positive attitude [ $(A O R=4.9,95 \% \mathrm{Cl}:(2.06,11.65)$ ], attending training [AOR=3.91, 95\% $\mathrm{Cl}:(1.48,10.32$ ], presence guideline of non-pneumatic anti-shock garment at their hospitals [AOR=2.57, $95 \% \mathrm{Cl}:(1.13,5.82$ )] were significantly associated with Midwives' knowledge of non-pneumatic anti-shock garment.

Conclusion and Recommendation: The knowledge Midwives' on non-pneumatic anti-shock garment was low. The identified factors that significantly associated with Midwives' knowledge of non-pneumatic antishock garment were positive attitude; attend training and presence of guideline of non-pneumatic antishock garments. The Midwives that involved in the maternity service should be improving their knowledge on non-pneumatic anti-shock garment.

\section{Introduction}

The Non-pneumatic Anti-Shock Garment (NASG) is a unique, simple, life-saving first-aid device made of neoprene and Velcro. Neoprene is a stretchy material, and Velcro is a "hook and loop" material that closes things tightly(1). Currently, it is the only tool first aids in stabilizing pulse and blood pressure after a woman has gone into shock from obstetric hemorrhage $(2,3)$.

The non-pneumatic anti-shock garments like bottom half suit and consists of three pairs the first of segments, the first segments are placed around the patient's legs and the second three segments are placed around her pelvis and abdomen during the application for postpartum hemorrhage(4).

Maternal mortality is the death of a woman during pregnant or within 42 days of termination of pregnancy, irrespective of the duration and site of the pregnancy, from any cause related to or provoked by the pregnancy but not from accidental or incidental causes" (5). Globally in 2017 every day, approximately 810 women died from preventable causes related to pregnancy and childbirth. From this death about $94 \%$ of all 
maternal deaths occur in low and lower middle-income countries. Sub-Saharan Africa and Southern Asia accounted for approximately 86\% (254 000) of the estimated global maternal deaths in 2017 (7).

According to the study done in eastern part of Ethiopia, about 311 deaths of reproductive aged women during the study period were reported. From this death, 72 (23.2\%) died during pregnancy or within 42 days of delivery. The overall estimated maternal mortality ratio was 324 per 100,000 live births (8).

Postpartum hemorrhage is one of the leading causes of maternal mortality and morbidity, accounted for approximately $27 \%$ of global maternal deaths, defined depend on amount of blood loss, is vaginal bleeding more than $500 \mathrm{ml}$ after vaginal delivery, blood loss of more than $1000 \mathrm{ml}$ after cesarean delivery and more than $1500 \mathrm{ml}$ after cesarean hysterectomy(9).

The postpartum hemorrhage is not only the direct cause of maternal of mortality, but it has also short and long term impacts like chronic illness, disability, increasing of death, poor growth and development of their children, hepatic dysfunction (10).

Midwives are the first point of contact for most women during pregnancy and labour and all women are at risk of postpartum hemorrhage, therefore midwives' knowledge of the non-pneumatic anti-shock garment which is very important for providing a quick and adequate way of emergency obstetric care during postpartum hemorrhage. In Ethiopia there is still lack of information about the knowledge Midwives to be specific about it use.Therefore this study seeks to assess the Midwives' knowledge of non-pneumatic antishock garment and associated factors in the management of post partum hemorrhage in Public Hospitals of Jimma Zone South West Ethiopia.

\section{Methods And Material}

\section{Study Area and Period}

The study was conducted in public hospitals of Jimma zone, Oromia regional state south-West Ethiopia. Jimma Zone located within latitude: $7^{\circ} 44^{\prime} 59.99^{\prime \prime} \mathrm{N}$ and longitude: $37^{\circ} 00^{\prime} 0.00^{\prime \prime} \mathrm{E}$. Jimma zone far $346 \mathrm{Km}$ from Addis Abbaba. Jimma is bordered on the South by the Southern Nations, Nationalities and Peoples Region, the Northwest by IlluAaba-bor Zone, on the north by East Walaga zone, and on the northeast by west Shewa zone; part of the boundary with EastShewa is defined by the Gibe River. The zone has a total area of 119,316 Square kilo meters. It has 21 woreda and 1 town administration with a total of 555 kebeles of which 515 of them are rural and 30 are urban. The population projection of 2014/15 of the zone is 3090112 with total reproductive age groups of 616380 .

In this zone there were seven public hospitals namely Jimma medical center, Shanan Gibe hospital, Agaro Hospital, Limmu Hospital, Seka Hospital, Omo Nada Hospital and Satama Hospital. The study was conducted from August 01 - 20, 202019.

\section{Study design}


Facility based a quantitative cross-sectional study design method was employed.

\section{Source and study population}

All Midwives who were working the seven public hospitals of Jimma Zone were source of populations. And all Midwives who were working public hospitals of Jimma Zone and fulfilled the selection criteria were study population.

\section{Selection criterion}

\section{Inclusion criterion}

All certified Midwives working in the labour and delivery wards by shift, regular bases and in night duty and at least worked in labour and delivery unit for 6 months and willing to participate were included.

\section{Exclusion criterion}

Midwives who were on annual leave during the study period were excluded.

\section{Sampling size and sampling procedure}

A total of 150 Midwives were included in the study by census sampling technique from all public hospitals of Jimma zone.

\begin{tabular}{|lll|}
\hline Sr.No & Name hospitals & No of Midwives \\
\hline 1. & JMC & 61 \\
\hline 2. & Shenen Gibe hospital & 20 \\
\hline 3. & Seka Hospital & 11 \\
\hline 4. & Omo Nada Hospital & 13 \\
\hline 5. & Limmu Hospital & 15 \\
\hline 6. & Agaro Hospital & 18 \\
\hline 7. & Satama Hospital & 12 \\
\hline & & Total \\
\hline
\end{tabular}

Table 1

The Total numbers of Midwives in each hospital 


\section{Operational Definitions}

Knowledge scale: A total of five questions (questions 3, 4, 5, 6, 7) were used to assess the respondents' knowledge. The maximum score was 16 and the minimum score was zero. The respondents score of total knowledge questions those who scored eight and above out of 16 or the percentage score were $50 \%$ and above have good knowledge and below $50.0 \%$ graded as having poor knowledge of non-pneumatic antishock garment (14).

\section{Measurements and Data Collection Procedure}

Aself-administered structured questionnaire was used to collect data from study participants. The instrument was adapted and developed from different literatures [12-16]. It was prepered in English version and the questionnaire contains four parts which include socio demographic characteristics, knowledge of non-pneumatic anti-shock garment, attitude regarding non- pneumatic anti-shock garment the responses consist five likert scales which were strongly agree, agree, neutral, disagree and strongly disagree. The five likert scale for analysis was become three likert scale. Strongly agree and agree became agree and disagree and strongly disagree became disagree and neutral and hospitals(organization) related questions. Before the actual data collection, the questionnaire was pre-tested on $10 \%$ of the total samples that was on 16 Midwives and appropriate corrections were made of some questions like logical order. The Experts were given for face validation and reliability was determined through internal consistency and reliable with Cronbach's alpha value 0.872 .

\section{Data process and Analysis}

Following data collection the completeness of the data was checked, data were coded, and entered to a computer using Epidata version 3.1 by double data enter and exported to SPSS version 23.0 for analysis. All independent variables were entered into bivariate analysis and those independent variables with a $p$ value $<0.25$ in bivariate analysis were used for multivariable analysis and finally variables with a $p$ value $<$ 0.05 in multivariable analysis were considered as statically significant of non-pneumatic anti-shock garment knowledge. Multi-collinearity was checked to see the linear correlation among the independent variables by using the variance inflation factor and standard error. None of the variables yield inflation factor $>10$ and standard error $>2$ and they were not dropped from multivariable analyses. Hosmer and Lemeshow's test was found to be insignificant and Omnibus test was significant which indicate that the model was fitted. Finally, the result of the analysis was presented in texts and tables as appropriate.

\section{Ethical considerations}

Before data collection, ethical clearance was obtained from the institutional review board of Jimma University, Institute of health and submitted to each hospital. The written consent was obtained from each participant that participation was voluntary and they have the right to withdraw at any time from the study. 
The informed consent was comprised the study purpose and procedures, potential risks and benefits, voluntary participation and right of withdrawal, the information provided by each respondent was kept strictly confidential.

\section{Results}

\section{Socio demographic characteristics}

A total of 160 questionnaires were distributed to the participants but only 150 were replied; the rest 10 did not fill the questionnaire correctly and excluded from the data analysis with response rate of $93.8 \%$.

Among the respondents, about 73 (48.7\%) were in the age group of 25-29. More than half of the respondents were male in sex (55.3\%) and not married (53.3\%). Majority of them were Oromo by ethnicity. Eighty six (41.0\%) were Muslim by religion and among the respondents one hundred eight (72\%) were bachelor degree holders in education status. One hundred forty eight $(70.5 \%)$ had $1-5$ years of work experiences (Table 1). 


\begin{tabular}{|c|c|c|}
\hline & Frequency & Percent \\
\hline \multicolumn{3}{|l|}{ Age in years } \\
\hline $20-24$ & 31 & 20.7 \\
\hline $25-29$ & 73 & 48.7 \\
\hline $30-34$ & 29 & 19.3 \\
\hline $35-39$ & 17 & 11.3 \\
\hline Sex & 83 & 55.3 \\
\hline Male & 67 & 44.7 \\
\hline Marital status & 70 & 46.7 \\
\hline Married & & \\
\hline \multicolumn{3}{|l|}{ Single } \\
\hline \multirow{2}{*}{$\begin{array}{r}\text { Ethnicity } \\
\text { Oromo }\end{array}$} & 105 & 70.0 \\
\hline & 25 & 16.7 \\
\hline Amhara & 8 & 5.3 \\
\hline Tigrai & 4 & 2.7 \\
\hline Others & 8 & 5.3 \\
\hline Religion status & 52 & 34.7 \\
\hline Muslim & 62 & 41.3 \\
\hline Orthodox & 32 & 21.3 \\
\hline Others & 4 & 2.7 \\
\hline \multirow{2}{*}{$\begin{array}{l}\text { Educational level } \\
\text { Bachelor degree }\end{array}$} & 42 & 28.0 \\
\hline & 108 & 72.0 \\
\hline \multirow{2}{*}{$\begin{array}{l}\text { Years of experience } \\
\text { 1-5 years }\end{array}$} & 97 & 64.7 \\
\hline & 46 & 30.7 \\
\hline \multicolumn{3}{|l|}{$6-10$ years } \\
\hline 11 years and above & 7 & 4.7 \\
\hline
\end{tabular}

Table 1 


\section{Respondents' Knowledge of Non-pneumatic Anti-Shock Garment:}

This study indicated that, one hundred twenty five (82.7\%) of respondents had the awareness of nonpneumatic anti-shock garment. Only forty four $(29.3 \%)$ of the respondents correctly mentioned that nonpneumatic anti-shock looks like bottom half of suit and less than (48\%) correctly mentioned that nonpneumatic anti-shock garment has six parts. concerning the function of non-pneumatic anti-shock garment, 59.3\% said that non-pneumatic anti-shock garment increases blood flow to vital organs and 54 . $7 \%$ said that non-pneumatic anti-shock garment stabilized women when she was already in shock. Relating to the knowledge criteria of the application of non-pneumatic anti-shock garment for women with postpartum hemorrhage about $50.7 \%$ said non-pneumatic anti-shock garment was applied when blood loss was greater than $750 \mathrm{ml}$ and said that non-pneumatic anti-shock garment removed from women when blood loss $<50 \mathrm{ml}$ and Systolic blood pressure $>100 \mathrm{mmhg}(42.7 \%)$. The overall knowledge of Midwives, $81(54 \%)$ of Midwives had good knowledge of non-pneumatic anti-shock garment (Table 2). 
Known NASG as it used for pph complication mgt

Yes

No

25

17.3

NASG look like

Gown

27

18

Trousers

79

52.7

Bottom half of suit

44

29.3

How many parts have the NASG

Four

32

21.3

Six

72

48

Eight

25

16.7

Nine

21

14

What is the advantage NASG? *

Prevent Shock

54.7

Stabilize the women in shock

82

54.7

Reverse shock

43

28.7

Decrease blood loss

65

Compress blood vessels

71

47.3

Increase blood flow to vital organs

89

59.3

Know proper use of NASG

Yes

91

60.7

No

59

39.3

Non-pneumatic anti-shock garment applied for women with PPH when.*

Bleeding $>750 \mathrm{ml}$

systolic blood pressure $<90 \mathrm{~mm}$

76

50.7

Pulse $>110 \mathrm{bpm}$. 
Blood loss $<50 \mathrm{ml} / \mathrm{hr}$,

Pulse $<100$ bpm

Systolic blood pressure $>100 \mathrm{mmhg}$

Normal shock index

Types of knowledge

Good knowledge

Poor knowledge

* Multiple responses are possible
64

55

64

42

81

69
42.7

36.7

42.7

28

\section{Table 2}

Knowledge NASG among Midwives who were working in Jimma Zone Public Hospitals South West Ethiopia, August 2019.

\section{Attitudes of Midwives towards non-pneumatic anti Shock Garment}

Concerning the attitudes of the respondents towardsof non-pneumatic anti-shock garment, about one hundred five (70\%) of the respondents agreed that non-pneumatic anti-shock garment is necessary for the management of postpartum hemorrhage in all settings of health facilities and $7.3 \%$ disagree. One hundred one (67.3\%) respondents agreed that non-pneumatic anti-shock garment can used along with standard treatment protocols of postpartum hemorrhage treatment and 9(6\%) disagreed. Regarding the total attitude of respondents, about $88(58.7 \%$ ) had positive attitudes towards non-pneumatic anti-shock garment (Table 3) 


\begin{tabular}{|c|c|c|c|}
\hline \multirow[t]{2}{*}{ Variables } & Agree & neutral & Disagree \\
\hline & $\mathrm{No}(\%)$ & No(\%) & No(\%) \\
\hline $\begin{array}{l}\text { The use of non-pneumatic anti shock garment is necessary for the } \\
\text { management of postpartum hemorrhage in all settings. }\end{array}$ & 105(70) & $34(22.7)$ & $11(7.3)$ \\
\hline $\begin{array}{l}\text { NASG can used along with standard treatment protocols of } \\
\text { postpartum hemorrhage. }\end{array}$ & 101(67.3) & $40(26.7)$ & $9(6)$ \\
\hline $\begin{array}{l}\text { NASG can be applied with minimum procedures in short period of } \\
\text { time. }\end{array}$ & $77(51.3)$ & $38(25.3)$ & $35(23.3)$ \\
\hline Removal NASG requires a lot of procedures that takes time. & $89(59.3)$ & $21(14)$ & $40(26.7)$ \\
\hline $\begin{array}{l}\text { Anti shock garment is only beneficial to people in the rural } \\
\text { areas/primary care settings }\end{array}$ & 19(12.7) & $41(27.3)$ & $90(60)$ \\
\hline Manual removal of placenta is possible with NASG in place & 103(68.7) & 23(15.3) & $24(16)$ \\
\hline $\begin{array}{l}\text { Anti-shock garment is effective in patients with cervical } \\
\text { lacerations }\end{array}$ & $71(47.3)$ & $55(36.7)$ & $24(16)$ \\
\hline $\begin{array}{l}\text { The garment should be a must in every } \\
\text { health care facility that has maternity } \\
\text { service }\end{array}$ & $100(66.6)$ & 19(12.7) & $31(20.7)$ \\
\hline \multirow[t]{2}{*}{ Types of attitude } & Positive & 88 & 58.7 \\
\hline & Negative & 62 & 41.3 \\
\hline
\end{tabular}

Table 3

Attitudes of Midwives towards Non-pneumatic anti-shock garment among Midwives who were working in Jimma Zone Publc Hospitals South West Ethiopia, August 2019

\section{Organizational related factors of the Midwives}

Concerning to training status of the respondents on non-pneumatic anti-shock garment forty five (30\%) of the respondents trained on the use of non-pneumatic anti-shock garment. From the totals about $60(40 \%)$ Midwives were working at general hospitals, $86(57.33 \%)$ of the respondents said that their hospitals have two and above number of non-pneumatic anti-shock garment and 70(42.7\%) participants have NASG guideline in their hospitals (Table 4). 


\begin{tabular}{|lll|}
\hline Characteristics & Frequency & Percent \\
\hline What is the level of your hospital? & 32 & 21.3 \\
Primary hospital & 60 & 40 \\
General hospital & 58 & \\
Tertiary hospital & & \\
\hline Training received staffs & & \\
\hline Yes & 45 & 30 \\
\hline No & 155 & 65 \\
\hline How many numbers NASG available at your hospital? & 64 & 42.67 \\
One & 86 & 57.33 \\
Two and above & & \\
\hline Have NASG guideline & & \\
Yes & & \\
No & 70 & 46.7 \\
\hline
\end{tabular}

Table 4

Distribution of participants in their organizational among Midwives who were working in Jimma Zone Public Hospitals South West Ethiopia, August 2019

\subsection{Factors associated with Midwives knowledge of Non- pneumatic anti-shock garment.}

Bivariate logistic regression was carried out to assess possible relationship between knowledge nonpneumatic anti-shock garment and factors associated with it among the Midwives who were working Public hospitals of Jimma Zone.

In this study Midwives who had positive attitude toward the non-pneumatic anti-shock garment were 4.9times more likely to have good knowledge of non-pneumatic anti-shock garment as compared to those who had negative attitude towards non-pneumatic anti-shock garment [ $\mathrm{AOR}=4.9,95 \% \mathrm{Cl}:(2.06,11.65)]$.

The other independent factor that statically associated with Midwives knowledge of non-pneumatic antishock garment was training. Midwives who have training on non-pneumatic anti-shock garment were 3.91 
times more likely have good knowledge about non-pneumatic anti-shock garment as compared to Midwives who have no training on non-pneumatic anti-shock garment (AOR: 3.91, 95\% Cl:(1.48, 10.32)].

Midwives' whose hospital had guideline of non-pneumatic anti-shock garment garment, were 2.57 times more likely have good knowledge of non-pneumatic anti-hock garment than with those Midwives' hospital had no guideline of non-pneumatic anti-shock garment. ( AOR: $2.57,95 \% \mathrm{Cl}$ : $(1.13,5.82)]$ (Table 5).

\begin{tabular}{|c|c|c|c|c|}
\hline \multirow{3}{*}{ Characteristics } & \multirow{3}{*}{ Categories } & \multicolumn{3}{|c|}{ Knowledge of NASG } \\
\hline & & Good & Poor & AOR 95\% \\
\hline & & $N(\%)$ & $N(\%)$ & \\
\hline \multirow{5}{*}{$\begin{array}{l}\text { Age } \\
\text { respondents in } \\
\text { years }\end{array}$} & $20-24$ & $18(12)$ & $13(8.67)$ & 1.00 \\
\hline & $25-29$ & $34(22.7)$ & $39(26)$ & \multirow{2}{*}{$\begin{array}{l}0.65(0.23 \\
1.82)\end{array}$} \\
\hline & $30-34$ & $21(14)$ & $8(5.33)$ & \\
\hline & \multirow[t]{2}{*}{$35-39$} & \multirow[t]{2}{*}{$8(5.33)$} & \multirow[t]{2}{*}{$9(6.0)$} & $(0.93,17.4)$ \\
\hline & & & & $0.36(.83,1.60)$ \\
\hline \multirow[t]{2}{*}{ Attitude } & positive attitude & $65(43.33)$ & 23(15.33) & \multirow{2}{*}{$\begin{array}{l}4.9(2.06 \\
11.65) \\
1.00\end{array}$} \\
\hline & Negative attitude & $16(10.66)$ & $46(30.66)$ & \\
\hline \multirow{2}{*}{$\begin{array}{l}\text { Training on } \\
\text { NASG }\end{array}$} & Yes & $43(28.67)$ & $10((6.67)$ & \multirow{2}{*}{$\begin{array}{l}3.91(1.48 \\
10.32)\end{array}$} \\
\hline & No & $38(25.33)$ & $59(39.33)$ & \\
\hline \multirow{2}{*}{$\begin{array}{l}\text { Educational } \\
\text { status }\end{array}$} & Diploma & $18(12.0)$ & $24(16.0)$ & 1.00 \\
\hline & BSc degree & $63(42.0)$ & $45(30.0)$ & \multirow{2}{*}{$\begin{array}{l}2.58(0.91 \\
7.32)\end{array}$} \\
\hline \multirow{3}{*}{$\begin{array}{l}\text { Guideline } \\
\text { presence }\end{array}$} & Yes & $49(32.67)$ & $21(14.0)$ & \\
\hline & No & $32(21.33)$ & $48(32.0)$ & $\begin{array}{l}2.57(1.13, \\
5.82)\end{array}$ \\
\hline & & & & 1.00 \\
\hline
\end{tabular}

Table 5

Multivariable logistic regression showing independent factors of Midwives' knowledge of non-pneumatic anti-shock garment among Midwives working in Jimma Zone Public Hospitals South West Ethiopia, August 2019

\section{Discussion}

Non-pneumatic anti-shock garment (NASG) can prevent the postpartum hemorrhage complication by decreasing blood flow to the lower extremities and increasing blood flow to vital organs like brain, heart and lung. 
The study revealed that $82.7 \%$ of the respondents have heard of the non-pneumatic anti -shock garment and majority of them first heard from the hospitals (54.2\%). More than half of the respondents had good knowledge (54\%) on non-pneumatic anti-shock garment about the description, its function, criteria for applying and removing and uses of non-pneumatic anti-shock garment. When this finding is compared with other study findings the awareness and the knowledge of the respondents was higher from Ondo state Nigeria in 2015 on 177 Midwives in which $66.67 \%$ of the respondents had awareness of non-pneumatic anti-shock garment and $45.80 \%$ have good knowledge about non-pneumatic anti-shock (12). However, this finding was lower when compared with the study finding in Bayelsa State Nigeria that all (100\%) and Ibadan Nigeria(96\%) of the study respondents have heard NASG and $65.18 \%$ had good knowledge onnonpneumatic anti-shock garment Bayelsa State and in Sokoto state about $64 \%$ respondents had good knowledge respectively $(16,13,14)$. The difference may be due sample size, also may be due to variation in sampling technique used.

Good knowledge of Midwives non-pneumatic anti-shock garment was seen among Midwives who had positive attitude. This implies that Midwives who had positive attitude toward the Non-pneumatic antishock garment were 4.9times more likely to have good knowledge on non-pneumatic anti-shock garment as compared to those who had negative attitude towards Non-pneumatic anti-shock garment. This may due the fact that Midwives who have positive attitude here is a big tendency to acquire to the knowledge of Non-pneumatic anti-shock garment to utilize to manage postpartum hemorrhage complication as one method because of non-pneumatic anti-shock garment is the best management postpartum hemorrhage complication. [AOR $=4.9,95 \% \mathrm{Cl}:(2.06,11.65)]$.

This study showed that good knowledge of Midwives non-pneumatic anti-shock garment was seen among Midwives who took training on non-pneumatic anti-shock garment as compared to those who have no training. Midwives who have training on the non-pneumatic anti-shock garment were 4.9 times more likely have good knowledge about non-pneumatic anti-shock garment than who have no training on nonpneumatic anti-shock garment. This may be due to the fact that attending training can help Midwives to get more knowledge about non-pneumatic anti-shock garment that who never know non-pneumatic antishock garment can get the knowledge of it and those who have information before training of NASG can more improve their knowledge of non-pneumatic anti-shock garment[ $\mathrm{AOR}=4.9,95 \% \mathrm{Cl}:(2.06,11.65)]$.

In this study other factor that statically associated with Midwives' knowledge of non-pneumatic was guideline of Non-pneumatic anti-shock garment. Midwives' whose hospital had guideline of non-pneumatic anti-shock garment garment were 2.57 times more likely have good knowledge of non-pneumatic anti-hock as compared to those Midwives' hospital had no guideline of non-pneumatic anti-shock garment. This may be due to the fact that the guideline of the non-pneumatic anti-shock garment contains the knowledge of non-pneumatic anti-shock garment in details. The Midwives that read the guideline can got the knowledge about its functions, criteria of application and removal and parts of NASG ( AOR: 2.57, 95\% Cl: $(1.13,5.82)$ ].

In this study the study participants were only Midwives that incorporated and factors that affecting the knowledge of non-pneumatic anti-shock garment were identified. These factors may not independently influence the knowledge of non-pneumatic anti-shock garment. So to improve these factors are

Page $14 / 17$ 
independently influence the knowledge of NASG, future study should be focus on identifying factors associated with knowledge of the NASG and also included all health care professionals that provide maternity services.

\section{Strength and limitations}

The study involved that included all Midwives. The questionnaire was prone to social desirability bias; hence it assesses self-reported regarding utilization of NASG, there might be over-reporting of a behavior. Lack of literature in Ethiopia adequate studies done out of Ethiopia on this topic make discussion difficult and failure to measure statistical significance on factor associated with knowledge of Midwives on Nonpneumatic anti-shock garment

\section{Conclusion}

This study showed that of the respondents' Knowledge of non-pneumatic anti shock garment for was low. The study also identified factors statically associated with Midwives knowledge of non-pneumatic antishock garment. The factors associated with Knowledge of Midwives about non-pneumatic anti-shock garment were having positive attitude toward NASG; attend training on non-pneumatic anti-shock garment and guideline of non-pneumatic anti-shock garment. Periodic training for health professionals on the use of non-pneumonic anti-shock garment for management of obstetric hemorrhage.

\section{Declaration}

\section{Availability of Data and Materials}

The spreadsheet data supporting the findings of this work is available at the hands of the corresponding authors

\section{Ethics Statement}

All procedures performed in studies involving human participants were in accordance with the ethical standards of the institutional and/or national research committee and with the declaration and its later amendments or comparable ethical standards. Before the commencement of the study, ethical approval was secured from the Jimma University Ethical Review Board. Written informed consent was obtained from all individual participants included in the study.

\section{Consent for publication}

The purpose of the study was explained to the study participants at the time of data collection and verbal consent was secured from each participant before the start of data collection. Confidentiality was ensured 
by not including names or other identifiers in the data collection tool. The right of the participants to refuse participation or not to answer any of the questions was respected.

\section{Conflict of Interests}

All authors declared that they have no conflict of interests.

\section{Funding}

Jimma University covered only the survey cost for this study and there is no any funding organization.

\section{Authors' Contribution}

Gemechu Terefe and Gadisa Bekele conceived and designed the protocol. Gemechu Terefe, contributed on developing proposal, data analysis, and checked the draft. Gemechu Terefe and Gadisa Bekele prepared manuscript. Both authors read and approved the final paper.

\section{Acknowledgements}

We would like to thank Public Hospitals of Jimma zone for all the help and support given for us during the data collection period. We also thank Jimma University institute of health for permitting us to conduct this study.

\section{Abbreviations}

ATSM: Active third stage management; NASG: Non-pneumatic Anti-shock Garment; PPH: postpartum hemorrhage; AOR: Adjusted Odd Ratio; JMC: Jimma Medical Center EAO: Extreme adverse outcome:

\section{References}

1. www.safemotherhood.ucsf.edu > 2014/08 > NASG-INTRODUCTION safe motherhood program -TrainerCOM

2. The WHO has recommended using NASG to help reduce maternal deaths in settings where definitive care is not immediately available and is included in WHO's Breakthrough Innovations that Can Save Women and Children Now.

3. Miller S, Bergel EF, El Ayadi AK, et al. Non-Pneumatic Anti-Shock Garment (NASG), a first-aid device to decrease maternal mortality from obstetric hemorrhage: a cluster randomized trial, PLOS One, 2013 8(10):764 - 677.

4. SULLEN MILLER Introduction to NASG safemotherhood.ucsf.edu IND LEARNER | FACILITY | @ 2013 
5. WHO Health statistics and information system maternal mortality ratio definitions. Retrieved 2017: Available from: http://www.who.int/healthinfo/statistics/indmaternal mortality/en/

6. World Health Organization, UNICEF, United Nations Population Fund (UNFPA). Managing complications in pregnancy and childbirth: a guide for midwives and doctors. 2nd ed. Geneva: World Health Organization; 2017.

7. Trendsin maternal mortality: 2000 to 2017: estimates by WHO, UNICEF, UNFPA, World Bank Group and the United Nations Population Division. Geneva: World Health Organization; 2019

8. Tesfaye et al. Magnitude, trends and causes of maternal mortality among reproductive aged women in Kersa health and demographic surveillance system, eastern Ethiopia BMC Women's Health, 2018,18:198

9. DC Dutta's Textbook of Obstetrics: Kolkata India, eighth edition 2015. Available from: https://www.academia.edu/36303073/Textbook_of_DC_Duttas_OBSTETRICS_8ed.

10. Abete T,Kebede BMisganaw, E, RogersN, Retrospectivestudy of birth outcome and prevalence postpartum morbidity among women who attendend for care in Gonder,North West Ethiopia j.androl ,2014; 3(125)

11. Effectiveness of Non-Pneumatic Anti-Shock Garment (NASG) in Preventing Shock-related Morbidity and Mortality in Severe Hemorrhagic Shock. Crit Care Obst Gyne. 2017;3:3.

12. OGBEYE GB, OHAERI BM, OLATUBI MI. Midwives knowledge and attitude towards the use of anti-shock garment in the control of post partum hemorrhage in selected hospitals in Ondo state. Int J Health Sci Res. 2015; 5(9):389-395.

13. Kolade OA, Tijjani WA, Oladeji MA, Ajibade LA. Midwives' knowledge and utilization of anti shock garment in prevention of postpartum haemorrhage shock at the university college hospital, Ibadan Nigeria. J Nurs Health Sci. 2014;3:9-16

14. Kombo SA, Shehu SB, Farooq MA, Yunusa A. Knowledge and Utilization of Antishock Garment in Prevention of Pospartum Haemorrhagic Shock in Specialist Hospital Sokoto, Sokoto State Nigeria DUJOPAS 4(2): 236 -244, 2018

15. Enuku ca, Adeyemo fo. Knowledge and use of anti-shock garment among midwives in central hospital, Benin City, Edo state. Lautech journal of Nursing. 2018:23.

16. Onasoga OA, Duke E, Danide IU, Jack-Ide IO. Midwives' knowledge and utilization of non pneumatic anti shock garment in reducing complication of postpartum hemorrhage is selected health care facilties in Bayelsa state Nigeria. IntJ Reproductive contraceptive Obstet Gynecol 2015;977-981 